$6{ }^{\mathrm{a}}$ Department of Food Science and Nutrition, University of Minnesota, 1334 Eckles Ave.,

$7 \quad$ St. Paul, MN, 55108, USA

$8{ }^{b}$ Department of Food, Environmental and Nutritional Sciences, Università degli Studi di

9 Milano, via G. Celoria 2, 20133, Milan, Italy

11 Science \& Human Nutrition Facility East Pullman, WA 99164, USA

$12{ }^{\mathrm{d}}$ Deceased, formerly at the Department of Food Science and Nutrition, University of

13 Minnesota, 1334 Eckles Ave., St. Paul, MN, 55108, USA

14

15

16

17

18

\section{Structural consequences of the interaction of puroindolines with gluten proteins}

\author{
Enoch T. Quayson ${ }^{\mathrm{a}}$, Alessandra Marti ${ }^{\mathrm{a}, \mathrm{b},}{ }^{*}$, Craig F. Morris ${ }^{\mathrm{c}}$, Mauro Marengo ${ }^{\mathrm{b}}$, \\ Francesco Bonomi $^{\mathrm{b}}$, Koushik Seetharaman ${ }^{\mathrm{d}}$, Stefania Iametti ${ }^{\mathrm{b}}$
}

${ }^{c}$ USDA-ARS Western Wheat Quality Laboratory, Washington State University, E-202 Food

*Corresponding author: $\quad$ Phone +3950316640 . Fax +3950316672

E-mail alessandra.marti@unimi.it 


\section{Abstract}

20 The effect of puroindolines (PINs) on structural characteristics of wheat proteins was 21 investigated in Triticum turgidum ssp. durum (cv. Svevo) and Triticum aestivum (cv. Alpowa) 22 and in their respective derivatives in which PIN genes were expressed (Soft Svevo) or the distal 23 end of the short arm of chromosome 5D was deleted and PINs were not expressed (Hard 24 Alpowa). The presence of PINs decreased the amount of cold-SDS extractable proteins and the 25 accessibility of protein thiols to specific reagents, but resulted in facilitated solvation of gluten 26 proteins, as detected by tryptophan fluorescence measurements carried out on minimally mixed

27 flour/water mixtures. We propose that PINs and gluten proteins are interacting in the grain or 28 flour prior to mixing. Hydrophobic interactions between PINs and some of the gluten proteins 29 modify the pattern of interactions among gluten proteins, thus providing an additional 30 mechanistic rationale for the effects of PINs on kernel hardness.

32 Keywords: kernel texture, puroindoline proteins, gluten aggregation, protein thiols

\section{Chemical compounds}

35 Sodium dodecyl sulfate (PubChem CID: 3423265); Dithiothreitol (PubChem CID: 446094);

36 Tris (PubChem CID: 6503); Bromophenol Blue (PubChem CID: 8272); 5,5'- dithiobis-2-

37 nitrobenzoic acid (PubChem CID: 6254); Coomassie blue R-250 (PubChem CID: 23693030);

38 Trifluoroacetic acid (PubChem CID: 6422); Acetonitrile (PubChem CID: 6342); 2-

39 mercaptoethanol (PubChem CID: 1567)

40 
44 DTT, Dithiothreitol; HMW, high molecular weight; LMW, low molecular weight; PINs,

45 Purindolines; SDS, Sodium Dodecyl Sulfate; SKCS, Single-Kernel Characterization System 46 


\section{Introduction}

48 Puroindolines (PINs) are wheat endosperm proteins that are present in nearly all taxa of the

49 Triticeae and Aveneae tribes (Jolly, Rahman, Kortt \& Higgings, 1993; Gautier, Cosson, Guirao,

50 Alary \& Joudrier, 2000). In spite of their low levels (0.1\% in soft wheat (Dubreil et al., 1998)),

51 PINs have been identified as determinants of wheat kernel texture (hardness) (Jolly et al., 1993;

52 Morris, 2002; Bhave \& Morris, 2008), i.e., of the force needed to crush the kernel. Kernel texture

53 and protein content affect end-use characteristics.

PINs expression is controlled by two genes (Pina-Dla and Pinb-Dla) located on the

55 distal end of the short arm of chromosome 5D (5DS), and encoding for Puroindoline A (PINA)

56 and Puroindoline B (PINB), respectively. Expression of the two genes results in soft kernel

57 texture, whereas the presence of only one functional gene or of mutations in either genes results

58 in hard kernel texture. Durum wheat - a tetraploid with no D chromosome - has no PIN genes,

59 and has higher kernel hardness than common wheat (Giroux \& Morris 1998).

60

The effects of PINs expression or deletion on milling and rheological properties of soft-

61 textured durum and hard-textured common wheat have also been investigated (Quayson, Atwell,

62 Morris \& Marti, 2016a; Murray, Kiszonas, Wilson \& Morris, 2016). Presence of PINs delayed

63 gluten protein aggregation, decreased dough stability and improved dough resistance, but had no

64 effect on dough extensibility (Quayson et al., 2016a). The production of soft-textured durum

65 could help increase its use both in traditional durum foods and unconventional ones, such as

66 leavened products (Morris et al., 2015). Soft-textured durum is reported to have milling

67 properties intermediate between soft wheat and hard wheat (Murray et al., 2016), resulting in

68 decreased energy requirement for milling compared to durum wheat (Morris et al., 2015). The

69 same study reported the successful use of soft-textured durum in the production of spaghetti and 
70 bread that were of the same or better quality than the reference products. PINs also have shown

71 to be relevant to gas cell stabilization and foam stability in baked products (Dubreil, Compoint \&

72 Marion, 1997).

73 Finnie, Jeannotte, Morris and Faubion (2010a) reported that wheat endosperm hardness

74 involves a four-way interaction between the starch granule surface, storage proteins, PINs, and

75 polar lipids. PINs are thought to bind to hydrophobic surfaces in the grain (either the starch

76 surface and/or the polar lipids) (Wall et al., 2010; Greenwell \& Schofield, 1986) through a Trp-

77 rich domain (Fiez, Wanjugi, Melnyk, Altosaar, Martin \& Giroux, 2009; Alfredo, Palombo,

78 Panozzo \& Bhave, 2014). Alfredo et al. (2014) also suggested the formation of PIN homo- or

79 hetero-dimers/oligomers via ionic, polar, and/or hydrophobic interactions between residues on

80 the exposed loops and helix surfaces of PINs.

81 During mixing, PINs supposedly detach from the starch granule surface and become

82 incorporated in dough (Finnie, Jeannotte, Morris, Giroux \& Faubion, 2010b) because - under

83 mixing conditions - lipids and PINs may have higher affinity for gluten than for the starch

84 granule surface (Finnie et al., 2010b). However, the type and manner of the association of PINs

85 with gluten protein is unknown, and no information is available on whether this association may

86 occur prior to mixing.

87 To gather information on the type of possible interactions between PINs and gluten 88 proteins in flour, this study aims at investigating the effect of PINs on aggregation of gluten 89 proteins, on protein solvation, and on the exposure of reporter amino acid sidechains in gluten 90 proteins. Among the sidechains most relevant from a practical standpoint are those of 91 hydrophobic residues that re-organize in different fashion during mixing of dough from hard and 92 soft wheat (Jazaeri, Bock, Bagagli, Iametti, Bonomi \& Seetharaman, 2015). The fluorescence of 
93 tryptophan sidechains has been indicated as an useful "reporter" of the structural status also of

94 gluten proteins (Bonomi, Mora, Pagani \& Iametti, 2004; Bonomi et al., 2012; Bonomi, Iametti,

95 Mamone \& Ferranti, 2013).

96 Cysteine residues also are of paramount relevance in formation and stabilization of the 97 gluten network through disulfide exchange processes. Accessibility of cysteine thiols in the 98 presence/absence of protein unfolding agents has been proposed as an index of network 99 compactness in various cereal-based products (Bonomi et al., 2012, 2013; Iametti, Marengo, 100 Miriani, Pagani, Marti \& Bonomi, 2013). By using conditions capable of dissociating weak 101 hydrophobic interactions in the presence/absence of a concomitant mechanical treatment, some 102 of us have attempted to unravel the network of covalent and non-covalent interprotein bonds 103 and the kinetics of their formation - in wheat-based products at various stages of processing 104 (Jazaeri et al., 2015; Quayson et al., 2016a, 2016b).

105 The study presented here relies on the availability of lines of Triticum turgidum ssp. 106 turgidum ssp. durum (cv. Svevo) and T. aestivum (cv. Alpowa), and of their derivatives in which 107 PIN genes were expressed (Soft Svevo) or deleted (Hard Alpowa). The use of these simplified 108 models and of the molecular approaches outlined above should contribute to improve current 109 understanding of the role of PINs in determining the gluten structural characteristics in wheat 110 flour, paving the way for further detailed studies on the molecular determinants of reported 111 effects of PINs' presence.

\section{2. Materials and Methods}


116 Wheat cultivars (cvs) Alpowa (soft wheat, T. aestivum L.), hard kernel Alpowa (Hard Alpowa),

117 durum wheat (T. turgidum L., ssp. durum) cv Svevo, and soft kernel durum wheat (Soft Svevo)

118 were used in the study. Hard Alpowa (proteins: $14.8 \pm 0.1 \mathrm{~g} / 100 \mathrm{~g}$ d.b.; SKCS: 98 ) is a back-cross

119 of seven $\left(\mathrm{BC}_{7}\right)$ near-isogenic lines derived from soft wheat Alpowa lines (protein: $12.3 \pm 0.2$

$120 \mathrm{~g} / 100 \mathrm{~g}$ d.b.: SKCS: 16) that lacks the distal portion of the short arm of chromosome 5D (Morris

121 \& King, 2008). Soft Svevo (protein: $14.8 \pm 0.2$ g/100g d.b., SKCS: 17) was developed by back-

122 crossing durum wheat cv. Svevo (protein: $15.9 \pm 0.2 \mathrm{~g} / 100 \mathrm{~g}$ d.b., SKCS: 73) and a homologous

123 translocation line involving Langdon durum and the soft wheat cultivar Chinese Spring (Morris,

124 Simeone, King \& Lafiandra, 2011). Alpowa and Hard Alpowa were grown in St. Paul (MN,

125 USA) in 2014. Svevo and Soft Svevo were grown in Pullman (WA, USA) in 2013. Wheat grains

126 were conditioned (14.5 g/100 g moisture for Alpowa and Soft Svevo; $15.5 \mathrm{~g} / 100 \mathrm{~g}$ for Hard

127 Alpowa; $16.5 \mathrm{~g} / 100 \mathrm{~g}$ moisture for Svevo), prior to milling with a Quadrumat Junior (C.W.

128 Brabender Inc., South Hackensack, NJ, USA) flour mill. After milling, the refined flour from 129 each sample was collected and used for analysis.

130

1312.2 Protein Aggregation

132 Protein aggregation in flours was investigated by a limited cold-solubilization approach, using 133 low concentrations of sodium dodecyl sulfate (SDS) and dithiothreitol (DTT) to break down 134 hydrophobic interactions and disulfide bonds, respectively, as outlined by Quayson, Marti, 135 Bonomi, Atwell and Seetharaman (2016b). Proteins were extracted in 0.05 mol/1 sodium 136 phosphate buffer, $\mathrm{pH} 7.0$, containing $0.1 \mathrm{~mol} / 1 \mathrm{NaCl}$ and $1 \% \mathrm{SDS}(\mathrm{w} / \mathrm{v})$ in the presence or in the 137 absence of $10 \mathrm{mmol} / \mathrm{l}$ DTT as indicated. A $1 \mathrm{ml}$ volume of the buffer was added to appropriate 138 amounts of flour $(\approx 1 \mathrm{mg}$ protein, as estimated from the nitrogen content) and the suspension was 
139 placed on a shaker for $60 \mathrm{~min}$ at $25^{\circ} \mathrm{C}$. After centrifugation at 3,000 $\times \mathrm{g}$ for $30 \mathrm{~min}$, the amount

140 of protein in the supernatant was determined using the RC-DC (Reducing Agent and Detergent

141 Compatible) Protein Assay (Bio-Rad, Hercules, CA, USA) with bovine serum albumin as a

142 standard.

143

$144 \quad 2.3$ SDS-PAGE

145 SDS-PAGE was carried out as reported by Bonomi et al. (2012) with minor modifications. For 146 assessing the overall protein profile, individual flour samples (15 $\mathrm{mg})$ were suspended in a 147 mixture of $0.2 \mathrm{ml}$ of buffer ( $50 \mathrm{mmol} / 1$ sodium phosphate, $50 \mathrm{mmol} / 1 \mathrm{NaCl}, 1 \% \mathrm{SDS}, \mathrm{pH} 7.0$ ) 148 and $0.2 \mathrm{ml}$ of SDS-PAGE reducing/denaturing buffer $(0.125 \mathrm{~mol} / 1 \mathrm{Tris}-\mathrm{HCl}, \mathrm{pH} 6.8,50 \%(\mathrm{w} / \mathrm{v})$ 149 glycerol, 1.7\% (w/v) SDS, 1\% (v/v) 2-mercaptoethanol, 0.01\% (w/v) Bromophenol Blue). The 150 resulting suspension was heated at $100^{\circ} \mathrm{C}$ for $20 \mathrm{~min}$, and clarified by centrifugation for $10 \mathrm{~min}$ 151 at $3000 \times g$ at room temperature. For characterization of the cold-SDS extracted proteins, soluble 152 extracts containing approximately $1 \mathrm{mg}$ protein (assessed colorimetrically as detailed in 153 subsection 2.2) were diluted (1/1 v/v) with SDS-PAGE denaturing buffer, and the mixture was 154 heated at $100^{\circ} \mathrm{C}$ for $10 \mathrm{~min}$. SDS-PAGE was carried out at $40 \mathrm{~mA}$ on a Mini-PROTEAN precast 155 gel (10\% porosity) in a Mini-PROTEAN apparatus (Bio-Rad, Richmond, VA, USA), loading 156 about 2 microgram proteins per lane. Gels were stained with Coomassie Blue R-250. 157 Puroindoline-enriched fractions were obtained from individual flours essentially by following the 158 Triton ${ }^{\circledR}$ X-114 solubilization procedure outlined by Day, Bhandari, Greenwell, Leonard \& 159 Schofield (2006), and were analyzed by SDS-PAGE as reported above for cold-SDS extracts.

$161 \quad 2.4$ Readily Accessible and SDS-Accessible Thiols 
162 Readily accessible thiols were determined by suspending $100 \mathrm{mg}$ of flour in $5 \mathrm{ml} 0.05 \mathrm{~mol} / 1$

163 sodium phosphate buffer, $\mathrm{pH} 7.2$, containing $0.1 \mathrm{~mol} / \mathrm{l} \mathrm{NaCl}$ and $0.5 \mathrm{mmol} / 1$ 5,5'- dithiobis-2-

164 nitrobenzoic acid (DTNB). When assessing SDS-accessible thiols, the above mixture also

165 contained 1\% SDS (Iametti, Bonomi, Pagani, Zardi, Cecchini \& D’Egidio, 2006). Suspensions

166 were placed on a shaker at $25^{\circ} \mathrm{C}$ for one hour, and then clarified by centrifugation at $10,000 \times g$

167 for $5 \mathrm{~min}$. The supernatant was filtered through a $10 \mu \mathrm{m}$ pore filter (Fisher Scientific, Pittsburg

168 VA, USA) and read at 412 nm (S8000; Biochrom, MA, USA) against a DTNB blank.

\subsection{Protein Solvation Studies}

171 Solid state tryptophan fluorescence in hydrated flour was measured at room temperature using a

172 front-face cell holder in a Perkin Elmer LS 55 Fluorescence Spectrometer (Perkin Elmer,

173 Llantrisant, UK). Solvation studies were performed by adding water to individual flour samples

174 (2.5 g each) to reach a final water content covering the $20-50 \%$ range in appropriate increments.

175 Samples were mixed in a beaker with a glass rod for 3 min as reported by Bonomi et al. (2004).

176 About $0.2 \mathrm{~g}$ of the resulting mixture were placed behind the quartz window of the measuring

177 cell, that was closed to spread the sample all across the measurement window. Tryptophan

178 fluorescence was monitored by taking emission fluorescence spectra from 350 to $450 \mathrm{~nm}$ with

179 excitation at $280 \mathrm{~nm}$ and emission and excitation slits set at $2 \mathrm{~nm}$.

181 2.6 Protein Molecular Weight Distribution

182 The molecular weight distribution of proteins in cold-SDS extracts from flour prepared in the

183 absence of disulfide reducing agents was determined by Size Exclusion High Performance

184 Liquid Chromatography (SE-HPLC), using a Prominence Shimadzu High-Performance Liquid 
Chromatograph (C196-E061N), with UV/VIS Diode Array Detector (Shimadzu, Columbia,

186 Maryland, US). Proteins were extracted from flour at room temperature by using 2\% SDS in 0.05

187 mol/1 sodium phosphate buffer, pH 6.8 essentially as indicated by Jazaeri et al. (2015). Flour

188 suspensions were shaken for one hour at $25^{\circ} \mathrm{C}$ and centrifuged for 30 minutes at $3,000 \times \mathrm{g}$ at

189 room temperature. The supernatant was filtered through a $0.2 \mu \mathrm{m}$ Phenomenex cellulose

190 membrane filter (St. Louis, MO, USA). An aliquot $(60 \mu 1)$ of the filtered extract was loaded on a

191 Phenomenex Yarra $3 \mu \mathrm{m}$ SEC 3000 HPLC column run at $30^{\circ} \mathrm{C}$ with $0.05 \%$ trifluoroacetic acid in

192 acetonitrile-water $(1: 1 \mathrm{v} / \mathrm{v})$ at a flow rate of $1 \mathrm{ml} / \mathrm{min}$. Elution was monitored at $214 \mathrm{~nm}$.

193

$194 \quad 2.7$ Statistical Analysis

195 Protein solubility, thiol accessibility, and molecular weight distribution were analyzed in 196 triplicate. Three spectra were collected for each sample in front-face fluorescence spectroscopy 197 measurements. Analysis of variance (ANOVA) was performed utilizing Statgraphics XV version 19815.1 .02 (StatPoint Inc., Warrenton, VA, USA). Samples were used as factors. When a factor 199 effect was found significant $(\mathrm{p} \leq 0.05)$, significant differences among the respective means were 200 determined using Fisher's Least Significant Difference (LSD) test.

201

\section{3. Results and Discussion}

203 3.1 Protein Profiles and Protein Aggregation Behavior

204 The effect of puroindoline genes expression or of the deletion of the 5DS distal portion on the 205 presence or absence of PINs was verified by analyzing the SDS-PAGE profiles of partially 206 purified PINs from the grains used in this study. Data in the supplementary materials (Fig.S1) 207 provide physical evidence for occurrence of the expected changes in the various grains used in 
208 this study, namely the absence of PINs in Triton X-114® extracts from hard-kernel grains and 209 the presence of PINs in extracts from soft-kernel grains, regardless of the species.

210 As shown in Fig.1, the presence/absence of PINs did not affect - within a given species -

211 the polypeptide pattern of proteins solubilized from the various flour by media of different

212 dissociating ability and under conditions where protein association was differently affected (vide

213 infra). The SDS-PAGE profiles in Fig. 1 underscore the expected relevance of species-specific

214 proteins. Differences in the protein profile among the two wheat species appear most relevant in

215 the 40-50,000 $\mathrm{Mr}$ region. In particular, a band at $\mathrm{Mr} \sim 42,000$ was evident in Alpowa and absent

216 in Svevo, whereas a band at $\mathrm{Mr} \sim 48,000$ was present in Svevo and absent in Alpowa,

217 independently of the presence/absence of PINs. These differences in gluten protein profiles may

218 account for the contrasting results from previous studies on the relation between kernel texture

219 and SDS-protein solubility in various grain accessions (Bushuk, Hay, Larsen, Sara, Simmons \&

220 Sutton, 1997; Hayta \& Schofield, 2004; Kuktaite, Larsson \& Johansson, 2004; Jazaeri et al., $2212015)$.

Cold-SDS protein extractability data from the various flour samples in the presence or 223 absence of DTT as a disulfide breaking agent are shown in Fig. 2. To the best of our knowledge,

224 this is the first time that these approaches have been used to investigate protein aggregation in 225 the same varieties in the presence or absence of PINs. PINs expression resulted in a significant $226(\mathrm{p} \leq 0.05)$ decrease in cold-SDS protein solubility in flour from T. durum grains (from 637 in 227 Svevo to $382 \mathrm{mg} / \mathrm{g}$ protein in Soft Svevo). In similar fashion, the 5DS distal end deletion resulted 228 in a significant $(\mathrm{p} \leq 0.05)$ increase in cold-SDS protein solubility in flour from $T$. aestivum grains 229 (from $422 \mathrm{mg} / \mathrm{g}$ protein in Alpowa to 688 in Hard Alpowa). 
Adding a reducing agent (DTT) to the SDS-containing buffer used for cold-extraction of

231 proteins resulted in a significant $(\mathrm{p} \leq 0.05)$ increase in protein solubility in all samples but Hard

232 Alpowa, where the observed increase was statistically not significant. The results obtained here

233 with cold-SDS as the dissociating agent used for breaking down non-covalent hydrophobic

234 interactions among aggregated proteins confirm the major role of interprotein disulfide bonds in

235 the stabilization of insoluble protein aggregates as observed with other chaotropes (Iametti et al.,

236 2006; Iametti et al., 2013; Bonomi et al., 2013). Some further considerations may be made in the

237 case of the Alpowa/Hard Alpowa system. The presence of PINs in Alpowa results in decreased

238 protein solubility in cold SDS (as also observed when PINs are expressed in Soft Svevo), and

239 brings back the sensitivity to DTT of protein solubility. Indeed, in the case of Hard Alpowa -

240 where purindolines are not present -, non-covalent interactions represent the most relevant

241 driving force in the formation and/or stabilization of the protein network.

242 It has to be noted that the solubility results discussed above were obtained on flour 243 suspensions, that is, in the absence of the mechanical unfolding steps associated with mixing

244 flour into a dough. Thus, interactions among PINs and gluten proteins may pre-exist in the grain

245 or flour itself, or may occur during the solvation step of proteins that occurs prior to dough

246 mixing. Of course, this assumption does not rule out the possibility that these interactions may

247 occur even if PINs are adhering to other types of macrostructures and /or macromolecules in the

248 kernel, as suggested in other previous studies (Wall, Wheeler, Smith, Figeys \& Altosaar, 2010;

249 Greenblatt \& Schofield, 1986).

250 From our solubility results, it seems reasonable to assume that the differences in protein

251 aggregation related to the presence/absence of PINs could involve more or less specific

252 interactions between PINs and those gluten proteins where specific functions are present. It 
seems reasonable to assume that kernel hardness may somehow relate to the resilience or

254 compactness of the protein network in the grain, as dictated by species-specific genetic factors.

255 When the nature of gluten components and their structure make hydrophobic interactions among

256 gluten proteins more relevant than disulfide bridges to the stabilization of inter-protein

257 interactions (as in Hard Alpowa), the expression of PINs leads to an increased compactness of

258 the protein aggregates, that in turn leads to a decreased cold-solubility in the presence of low

259 SDS concentrations and in increased sensitivity to DTT of protein extractability (as observed in

260 Alpowa). The same reasoning may be applied to the results reported here from the Svevo durum

261 wheat, although in this case the contribution of disulfide bridges to interprotein interactions

262 remains appreciable even when PINs are present. It is also reasonable to assume that some

263 specific proteins or protein classes within individual grain species (as made also evident by the

264 SDS-PAGE tracings in Fig. 1) may be playing a prominent role in explaining changes related to

265 the presence/absence of PINs. The nature of the gluten proteins relevant to the hypothetical

266 interaction with PINS and the molecular determinants of the interaction are currently being

267 investigated.

2693.2 Accessibility of protein thiols

270 The accessibility of cysteine thiols in the various flour samples is shown in Fig. 3. It has to be

271 noted that the approach used for these studies is capable of detecting accessible thiols regardless

272 of protein solubility, and has proven useful for indicating the compactness of a protein network

273 in a number of food systems of different complexity whenever thiol-containing proteins are

274 present (Iametti et al., 2006; Iametti et al., 2013; Bonomi et al., 2013).

275 The compactness of the protein organization in Alpowa - as indicated by the low protein

276 solubility discussed in the previous subsection - is reflected in the low accessibility of cysteine 
277 thiols observed in the absence of SDS. Conversely, the absence of PINs in Hard Alpowa makes it

278 possible to access - even in the absence of SDS - the thiol groups of cysteine residues that were

279 otherwise likely buried within protein aggregates. The content in readily available protein thiols

280 in Hard Alpowa ( $4.17 \pm 0.55$ micromol thiols/g protein) was indeed twice that in Alpowa $(2.12 \pm$

2810.55 micromol thiols/g protein). The same considerations may apply to Svevo and Soft Svevo,

282 where the effects of PIN presence/absence are less marked $(3.19 \pm 0.23 v s 2.6 \pm 0.36$ micromol

283 thiols/g protein).

284 In all flours, the number of accessible thiols increased upon treatment with low SDS

285 concentrations at room temperature. However, the SDS-dependent increase in thiol accessibility

286 appears more pronounced in the presence of PINs. This behavior is particularly evident when

287 comparing Alpowa and Hard Alpowa, and confirms the relevance of hydrophobic interactions as

288 the major stabilizing element of interprotein interactions when PINs are present. Once again, it

289 has to be noted that the differences in terms of readily accessible and SDS-accessible thiols that

290 are evident in Fig. 3 may relate to the different protein profiles in the two species (see Fig.1).

292 3.3 Protein solvation

293 The emission maximum of tryptophan fluorescence is indicative of the polarity of the chemical

294 environment around the tryptophan side chains. The tryptophan emission maximum shifts

295 towards higher wavelengths as the polarity of the environment increases. Front-face (solid state)

296 fluorescence spectroscopy has proven useful in establishing the extent of contribution of

297 hydrophobic interactions to the gluten protein network in dough and in defining the nature and

298 extents of the structural rearrangements that accompany solvation of proteins in wheat-based

299 materials (Bonomi et al., 2004; Huschka, Bonomi, Marengo, Miriani \& Seetharaman, 2012). 
In this study, front-face tryptophan fluorescence was used to understand the possible role

301 of PINs on hydrophobic interactions in minimally mixed solvated flours. As pointed out in

302 previous studies (Bonomi et al., 2004; Jazaeri et al., 2015), formation of an extended protein

303 network in dough required a much higher level of mechanical stress than the one used here.

304 Thus, the observed interactions reported here may be seen as representative of those occurring in 305 solvated flour.

306 Before water was added to the various flours, expression of PINs had no relevant effects

307 on the tryptophan emission maximum in T. durum, as did the 5DS distal end deletion in $T$.

308 aestivum (see supplementary figure S1). In all cases, addition of water to flours resulted in

309 protein "swelling" and in increased tryptophan exposure to the solvent, causing a rise in

310 fluorescence intensity and a red-shift of the fluorescence emission maximum as water content of

311 the minimally mixed flour increased (Bonomi et al., 2004; Huschka et al., 2012). The

312 dependence of changes in tryptophan environment on the water content was evaluated by

313 calculating the ratio between fluorescence intensities measured at wavelength typical of the

314 water-exposed tryptophans $(380 \mathrm{~nm})$ and of those located in a non-polar environment $(340 \mathrm{~nm})$,

315 as reported by Bonomi et al. (2004, 2012). In this regard, the 380/340 ratio takes into account

316 both the shift in fluorescence emission maximum and the change in fluorescence intensity.

317 The calculated 380/340 ratios for the various samples at increasing moisture content are

318 shown in Fig. 4. The different sensitivity of the $380 / 340$ to increasing water content confirms

319 previous reports on the different solvation behavior of protein in durum and common wheat

320 (Bonomi et al., 2004). However, the expression of PINs has a remarkable effect on the sensitivity

321 of the structural organization of proteins to increased water availability, that could be quantitated

322 by estimating a solvation midpoint from the curves presented in Figure 4 . When PINs are 
323 present, protein solvation occurs at sensibly lower water levels (solvation midpoints at $27.5 \%$

324 water in Soft Svevo and $28.5 \%$ in Alpowa) than in the absence of PINs (solvation midpoints at $32530.0 \%$ water in Svevo and $33.5 \%$ in Hard Alpowa). This confirms that the presence of PINs 326 despite their low relative abundance - negatively affects the compactness of the protein network 327 in grains from different species, as also indicated by the molecular indices presented and 328 discussed in the previous subsections.

\subsection{Size distribution of SDS-solubilized proteins}

331 Data in the previous subsections indicate that the presence/absence of PINs affects the 332 aggregation state of gluten. Therefore, we attempted to verify whether the presence/absence of 333 PINs affected the molecular weight distribution of cold-SDS-extractable proteins obtained from

334 flour treated at room temperature in the absence of disulfide reducing agents. All the resulting 335 chromatograms showed three prominent peaks that were designated as high molecular weight 336 (HMW) components, low molecular weight (LMW) components, and other proteins, in analogy 337 to that reported by Jazaeri et al. (2015). These fractions are identified by vertical thin lines in the 338 two panels of Fig. 5. Expression of PINs decreased the amount of SDS-extractable HMW and LMW, as

340 indicated by the lower overall content of cold-SDS extractable proteins in Soft Svevo than in 341 Svevo (Fig. 5A). Conversely, deletion of 5DS distal end resulted in higher cold-SDS extractable 342 LMW and HMW in Alpowa than in Hard Alpowa (Fig. 5B). Thus, the results in Fig. 5 suggest 343 that presence of PINs facilitates formation of compact large molecular weight aggregates, 344 confirming the cold-SDS solubility data in Fig. 2.

PINs also affect the aggregation of gluten proteins at mesoscopic level, as shown by the 346 effects of PINs absence/presence on the LMW-to-HMW ratio, as calculated from integration of 
347 the corresponding chromatographic peaks. The values of this ratio were: $1.92 ; 2.15 ; 1.95$; and

3482.05 for Svevo, Soft Svevo, Alpowa, and Hard Alpowa, respectively. In the case of the

349 Svevo/Soft Svevo comparison, changes in this ratio were related to a decrease in the HMW

350 fraction, that was likely preferentially converted to non-extractable units in the presence of PINs

351 (Fig 5A and Fig. 2) (Veraverbeke et al., 2000a,b; Don et al., 2006). The 5DS distal end deletion

352 in Hard Alpowa facilitates the SDS-dependent breakdown of aggregates by, and the proteins

353 solubilized from Hard Alpowa under these conditions are characterized by an increase in their

354 LMW content with respect to HMW (Fig. 5B).

355 Don, Lichtendonk, Plijter, van Vliet and Hamer (2005) had demonstrated that the amount

356 of cold-SDS extractable LMW and HMW are directly related to the LMW and HMW in the so-

357 called Glutenin Macro-Polymer (GMP). Low molecular weight glutenin subunits (LMW-GS)

358 and high molecular weight glutenin subunits (HMW-GS) of GMP have been suggested to

359 associate within or between themselves to form large non-extractable aggregates (Veraverbeke,

360 Larroque, Bekes \& Delcour, 2000a, 2000b; Don, Mann, Bekes \& Hamar, 2006). From a practical

361 standpoint, increased levels of cold-SDS extractable proteins have been associated with good

362 baking quality (Weegels, van de Pijpekamp, Gaveland, Hamar \& Schofield, 1996), as reported

363 for Soft Svevo (Morris et al., 2015), and an increased concentration of HMW in proteins

364 unextractable in cold-SDS has been reported to have a positive effect on baking quality (Don et 365 al., 2006).

367 4. Conclusions

368 The present study highlights that PINs have an impact on gluten protein interactions in flour.

369 PINs enhanced gluten protein aggregation, resulting in decreased SDS extractability, decreased

370 thiols accessibility, and increased LMW-to-HMW ratio in cold-SDS extractable fractions. PINs 
371 also affected the interaction of gluten proteins with added water, as assessed through the solvent

372 accessibility of amino acid side chains that are considered as "reporters" of protein structural

373 organization. It is worth remembering here that this type of evidence was gathered on flour

374 aqueous suspensions in the absence of significant mechanical deformation of the relevant

375 proteins, suggesting that these interactions may occur in the grain and in the flour prior to

376 mixing.

377 No association or interaction of PINs with gluten proteins in flour was suggested in

378 previous reports. We suggest here that PINs may associate in the grain also with gluten proteins,

379 promoting the formation of highly compact supra-macromolecular aggregates stabilized by local

380 and very tight hydrophobic interactions. In this frame, and in consideration of the highly

381 hydrophobic character of PINs and of their low abundance with respect to gluten proteins, it is

382 tempting to speculate that PINs may provide some sort of "hydrophobic nucleus" for the

383 formation of protein aggregates of high compactness. It seems reasonable to assume that gluten

384 proteins should represent the most relevant constituent of these aggregates, and that their own

385 polypeptide composition (and, likely, structural features) should play a significant role in

386 determining the properties of the resulting system. Of course, the association of PINs and gluten

387 proteins does not rule out a possible role of other flour components (either polysaccharides or

388 lipids (Wallet al., 2010) in the formation or stabilization of multi-component aggregates.

389 A possible view of the interactions occurring among PINs and other grain proteins in flour

390 is hypothesized in the highly simplified scheme in Fig. 6. In the presence of PINs, the

391 hydrophobic interactions involving PINs and some gluten proteins lead to a localized

392 strengthening of the protein network. Although not accounted for in the necessarily schematic 
view presented in Figure 6, our gel-permeation data suggest a prominent involvement of HMW

394 components in these interactions.

395 When PINs are absent, the same hydrophobic regions on gluten proteins become available

396 for interactions among gluten proteins themselves, thus stiffening the protein network. In other

397 words, in a more pictorial representation, the same amount of rope (gluten proteins) may be

398 organized as a net (i.e., loose, fluffy, and easy to access, but difficult to untangle) as opposed to

399 bundles (physically stiffer than a net, but allowing easier removal of individual lengths of rope).

400 Relating these concepts to the whole issue of grain hardness is far from straightforward, given

401 the fact that these relationships reportedly involve other macromolecular components of the grain

402 (Greenblatt \& Schofield, 1986; Wall et al., 2010; Fiez et al, 2009; Alfredo et al., 2014).

403 It seems reasonable that proteins involved in interacting with PINs at the "structural knots"

404 hypothesized in Fig. 6 may be species-specific or even cultivar-specific. This hypothesis will

405 have to be verified by using some of the approaches presented here in studies on other types of

406 grains, including varieties that are characterized by a different PINs content, or that are known to

407 express (either exclusively or preferentially) one specific PIN isoform. Elucidating these aspects

408 will require further investigation, also in consideration of the possibility that components or

409 structures of non-protein nature may be involved in PIN-mediated interactions, and of the

410 additional possibility that PINA or PINB can have different sets of interactors. Addressing the

411 impact of PINs expression or 5DS deletion on the expression of specific protein fractions and/or

412 on the kinetics of protein synthesis and deposition in grains represents an another - and still non-

413 explored field of investigation.

414 From a more practical standpoint, we are currently taking advantage of recent

415 methodological developments (Quayson, Marti \& Seetharaman, 2014; Quayson et al., 2016a) to 
416 investigate how proteins in the different flours considered in this study behave when these same

417 flours are mixed into dough. Hopefully, these studies will also provide insights on the possible

418 impact of PINs on the structural modifications accompanying formation of a gluten protein

419 network upon mixing, that is, when mechanical unfolding of proteins and redistribution of polar

420 and non-polar components occurs.

421

422

\section{References}

423 Alfred, R. L., Palombo, E. A., Panozzo, J. F., \& Bhave, M. (2014). The co-operative interaction

424 of puroindolines in wheat grain texture may involve the hydrophobic domain. Journal of $425 \quad$ Cereal Science, 60,323-330.

426 Bhave, M., \& Morris, C. F. (2008). Molecular genetics of puroindolines and related genes: allelic diversity in wheat and grasses. Plant Molecular Biology, 66, 205-219.

428 Bonomi, F., Iametti, S., Mamone, G., \& Ferranti, P. (2013). The performing protein: Beyond wheat proteomics? Cereal Chemistry, 90,358-366.

Bonomi, F., D’Egidio, M. G., Iametti, S., Marengo, M., Marti, A., Pagani, M. A., \& Ragg, E. M. (2012). Structure-quality relationship in commercial pasta: A molecular

Bonomi, F., Mora, G., Pagani, M. A., \& Iametti, S. (2004). Probing structural features of water-insoluble proteins by front-face fluorescence. Analytical Biochemistry, 329, $104-111$.

Bushuk, W., Hay, R. L., Larsen, N. G., Sara, R. G., Simmons, L. D., \& Sutton, K. H. (1997). Effect of mechanical dough development on the extractability of wheat storage proteins from bread dough. Cereal Chemistry, 74, 389-395. 
439 Day, L., Bhandari, D. G., Greenwell, P., Leonard, S. A. \& Schofield, J. D. (2006).

440 Characterization of wheat puroindoline proteins. FEBS Journal, 273, 5358-5373.

441 Dubreil, L., Meliande, S., Chiron, H., Compoint, J-P., Quillien, L., Branlard, G., \& Marion, 442 D. (1998). Effect of puroindoline on the breadmaking properties of wheat flour.Cereal $443 \quad$ Chemistry, 75, 222-229.

444 Dubreil, L., Compoint, J. P., \& Marion, D. (1997). Interaction of puroindolines with wheat 445 flour polar lipids determines their foaming properties. Journal of Agricultural and $446 \quad$ Food Chemistry, 45,108-116.

447 Don, C., Mann, G., Bekes, F., \& Hamar, R. J. (2006). HMW-GS affect the properties of glutenin 448 particles in GMP and thus flour quality. Journal of Cereal Science, 44,127-136.

449 Don, C., Lichtendonk, W. J., Plijter, J. J., van Vliet, T., \& Hamer, R. J. (2005). The effect 450 of mixing on glutenin particle properties: aggregation factors that affect gluten 451 function in dough. Journal of Cereal Science, 41, 69-83.

452 Fiez, L., Wanjugi, H. W., Melnyk, C. W., Altosaar, I., Martin, J. M, \& Giroux, M. J. 453 (2009). Puroindolines co-localize to the starch granule surface and increase seed454 bound polar lipid content. Journal of Cereal Science, 50, 91-98.

455 Finnie, S. M., Jeannotte, R., Morris, C. F., \& Faubion, J. M. (2010a). Variation of polar 456 lipid composition among near-isogenic wheat lines possessing different puroindoline 457

458 Finnie, S. M., Jeannotte, R., Morris, C. F., Giroux, M. J., \& Faubion, J. M. (2010b). 459 Variation of polar lipids located on the surface of wheat starch. Journal of Cereal $460 \quad$ Science, $51,73-80$. 
Gautier, M-F, Cosson, P., Guirao, A., Alary, R., \& Joudrier, P. (2000). Puroindoline genes are highly conserved in diploid ancestor wheats and related species but absent in tetraploid Triticum species. Plant Science, 153, 81-91.

Giroux, M. J., and Morris, C. F., 1998. Wheat grain hardness results from highly conserved mutations in the friabilin components puroindoline a and b. Proceedings of the National Academy of Sciences, 95, 6262-6266.

Greenwell, P., \& Schofield, J. 1986. A starch granule protein associated with endosperm softness in wheat. Cereal Chemistry,63, 379-380.

Hayta, M., \& Schofield, J. D. (2004). Heat and additive induced biochemical transitions in gluten from good and poor breadmaking quality wheats. Journal of Cereal Science, 40, 245-256.

Huschka, B., Bonomi. F., Marengo, M., Miriani, M., \& Seetharaman, K. (2012). Comparison of lipid effects on structural features of hard and soft wheat flour proteins assessed by front-face fluorescence. Food Chemistry, 133, 1011-1016.

Iametti, S., Marengo, M., Miriani, M., Pagani, M. A., Marti, A., \& Bonomi, F. (2013). Integrating the information from proteomic approaches: A "thiolomics" approach to assess the role of thiols in protein-based networks. Food Research International, 54, 980-987.

Iametti, S., Bonomi, F., Pagani, M. A., Zardi, M., Cecchini, C \& D’Egidio, M. G. (2006). Properties of protein and carbohydrate fractions in immature wheat kernels. Journal of Agricultural and Food Chemistry, 54, 10238-10244. 
482

483

484

485

486

487

488

489

490

491

492

493

494

495

496

497

498

499

500

501

502

503

504

Jazaeri, A., Bock, J. E., Bagagli, M., P., Iametti, S., Bonomi, F., \& Seetharaman, K. (2015).

Structural modifications of gluten proteins in strong and weak wheat dough during mixing. Cereal Chemistry, 92, 105-113.

Jolly, C. J., Rahman, S., Kortt, A. A., \& Higgings, T. J. V. (1993). Characterization of the wheat Mr 15000 "grain softness protein" and analysis of the relationship between its accumulation in the whole seed and grain softness. Theoretical and Applied Genetics, $86,589-597$.

Kuktaite, R., Larsson, H., \&Johansson, E. (2004). Variation in protein composition of wheat flour and its relationship to dough mixing behavior. Journal of Cereal Science, 40, 31-39.

Morris, C. F., Casper, J., Kiszonas, A. M., Fuerst, E. P., Murray, J., Simenone, M. C., \& Lafiandra, D. (2015). Soft kernel durum wheat. A new bakery ingredient? Cereal Foods World, 60, 76-83.

Morris, C. F. (2002). Puroindolines: The molecular genetic basis of wheat grain hardness. Plant Molecular Biology, 48, 663-647.

Morris, C. F., Simeone, M. C., King, G. E., \& Lafiandra, D. (2011). Transfer of soft kernel texture from Triticum aestivum to durum wheat, Triticum lundidurum ssp. durum. Crop Science, 51, 114-122.

Morris, C.F., \& King, G. E. (2008). Registration of hard kernel puroindoline allele nearisogenic line hexaploid wheat genetic stocks. Journal of Plant Registration, 2, 67-68.

Murray, J.C., Kiszonas, A.M., Wilson, J.D., \& Morris, C.F. (2016). The effect of soft kernel texture on the milling properties of soft durum wheat. Cereal Chemistry, 93, $513-517$. 
Quayson, E.T., Atwell, W., Morris, C.F., \& Marti, A. (2016a). Empirical rheology and pasting properties of soft-textured durum wheat (Triticum turgidum ssp. durum) and hard-textured common wheat (T. aestivum). Journal of Cereal Science, 69, 252-258.

508 Quayson, E. T., Marti, A., Bonomi, F., Atwell, W., \& Seetharaman, K. (2016b). Structural modification of gluten proteins in strong and weak wheat dough as affected by mixing

$510 \quad$ temperature. Cereal Chemistry, 93, 189-195.

511 Veraverbeke, W.S., Larroque, O.R., Bekes, F., \& Delcour, J. A. (2000a). In vitro polymerization

512 of wheat glutenin subunits with inorganic oxidizing agents. I. Comparison of single-step and 513 stepwise oxidations of high molecular weight glutenin subunits. Cereal Chemistry, 77, 582$514 \quad 588$.

515 Veraverbeke, W.S., Larroque, O. R., Bekes, F., \& Delcour, J. A. (2000b). In vitro polymerization 516 of wheat glutenin subunits with inorganic oxidizing agents. II. Comparison of single-step and stepwise oxidations of high molecular weight glutenin subunits. Cereal Chemistry, 77,

Wall, M. L., Wheeler, H. L., Smith, J. C., Figeys, D., \& Altosaar, I. (2010). The tryptophan-rich domain of puroindoline is directly associated with the starch granule surface as judged by tryptic shaving and mass spectrometry. Journal of Cereal Science, 52, 115-120.

522 Weegels, P. L., van de Pijpekamp, A. M., Gaveland, A., Hamar, R.J. \& Schofield, J.D. 523 (1996). Depolymerization and repolymerization of wheat glutenin during dough 524 processing. I. Relationship between GMP content and quality parameters. Journal of 525 Cereal Science, 23, 103-111. 
526 Figure 1. SDS-PAGE of extractable proteins in various flour samples. 1: proteins solubilized in 527 buffered $0.85 \% \mathrm{SDS}$ and $60 \mathrm{mM}$ 2-mercaptoethanol upon treatment at $100^{\circ} \mathrm{C}$ for $10 \mathrm{~min} ; 2$ :

528 proteins solubilized in buffered $1 \% \mathrm{SDS}$ upon treatment at $25^{\circ} \mathrm{C}$ for $60 \mathrm{~min}$; 3: proteins 529 solubilized in buffered $1 \% \mathrm{SDS}$ and $10 \mathrm{mmol} / 1 \mathrm{DTT}$ upon treatment at $25^{\circ} \mathrm{C}$ for $60 \mathrm{~min}$. Equal

530 volumes of each extract (corresponding about 2 microgram protein, as calculated from the 531 protein content in each flour) were loaded in each lane.

533 Figure2. Protein aggregation in the various flour samples. Proteins were solubilized in 1\% 534 buffered SDS upon treatment at $25^{\circ} \mathrm{C}$ for $60 \mathrm{~min}$ in the presence/absence of $10 \mathrm{mmol} / 1$ 535 DTT as indicated. Error bars refer to standard deviation $(n=3)$. Different letters above each 536 column indicate a statistically significant difference $(p \leq 0.05)$.

538 Figure 3. Conditional accessibility of protein thiols in the various flour samples. Flour 539 samples were incubated for $60 \mathrm{~min}$ at $25^{\circ} \mathrm{C}$ with $0.5 \mathrm{mmol} / 1 \mathrm{DTNB}$ in $50 \mathrm{mmol} / 1$ phosphate 540 buffer ( $\mathrm{pH} 7.2$, containing $0.15 \mathrm{~mol} / 1 \mathrm{NaCl}$ ) in the presence/absence of $1 \%$ SDS as 541 indicated. Error bars refer to standard deviation $(n=3)$. Different letters above each column 542 indicate a statistically significant difference $(p \leq 0.05)$.

544 Figure 4. Changes in the front-face tryptophan fluorescence intensity at 340 and $380 \mathrm{~nm}$ 545 occurring upon protein solvation in various flour samples. Curves are a polynomial best fit 546 to the actual data. Error bars refer to standard deviation $(n=3)$. 
548 Figure 5. Gel permeation profiles of proteins solubilized from the various flours upon incubation 549 for $60 \mathrm{~min}$ at $25^{\circ} \mathrm{C}$ in $50 \mathrm{mmol} / 1$ phosphate buffer, $\mathrm{pH} 6.8$, containing $2 \% \mathrm{SDS}$ in the absence of 550 DTT.

552 Figure 6. A highly simplified schematic representation of the different organization of gluten 553 proteins in the presence/absence of purindolines (red circles). The same number of two types of 554 gluten proteins (identified by green and brown colors) is present in both the upper and the lower 555 part of the scheme. In each protein, color intensity relates to the hydrophobicity of a given 556 structural region. Cysteine-rich regions in gluten proteins are in yellow, but possible disulfides 557 are not identified. Grain components other than proteins (and additional protein constituents) are 558 not shown, for the sake of clarity. 


$$
\mathrm{Mr} * 10^{-3}
$$

94

66

45

30

20

14

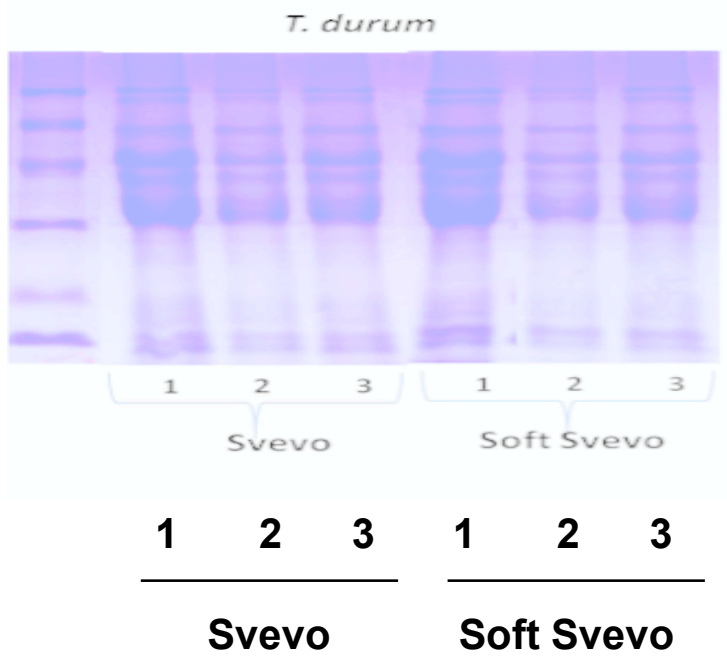

$\mathrm{Mr} * 10^{-3}$

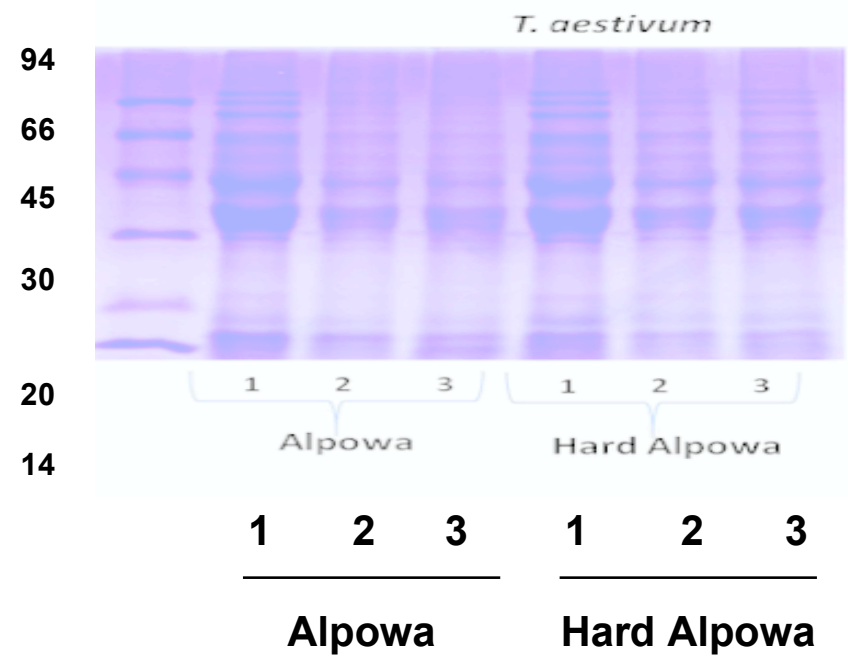

Figure 1. 


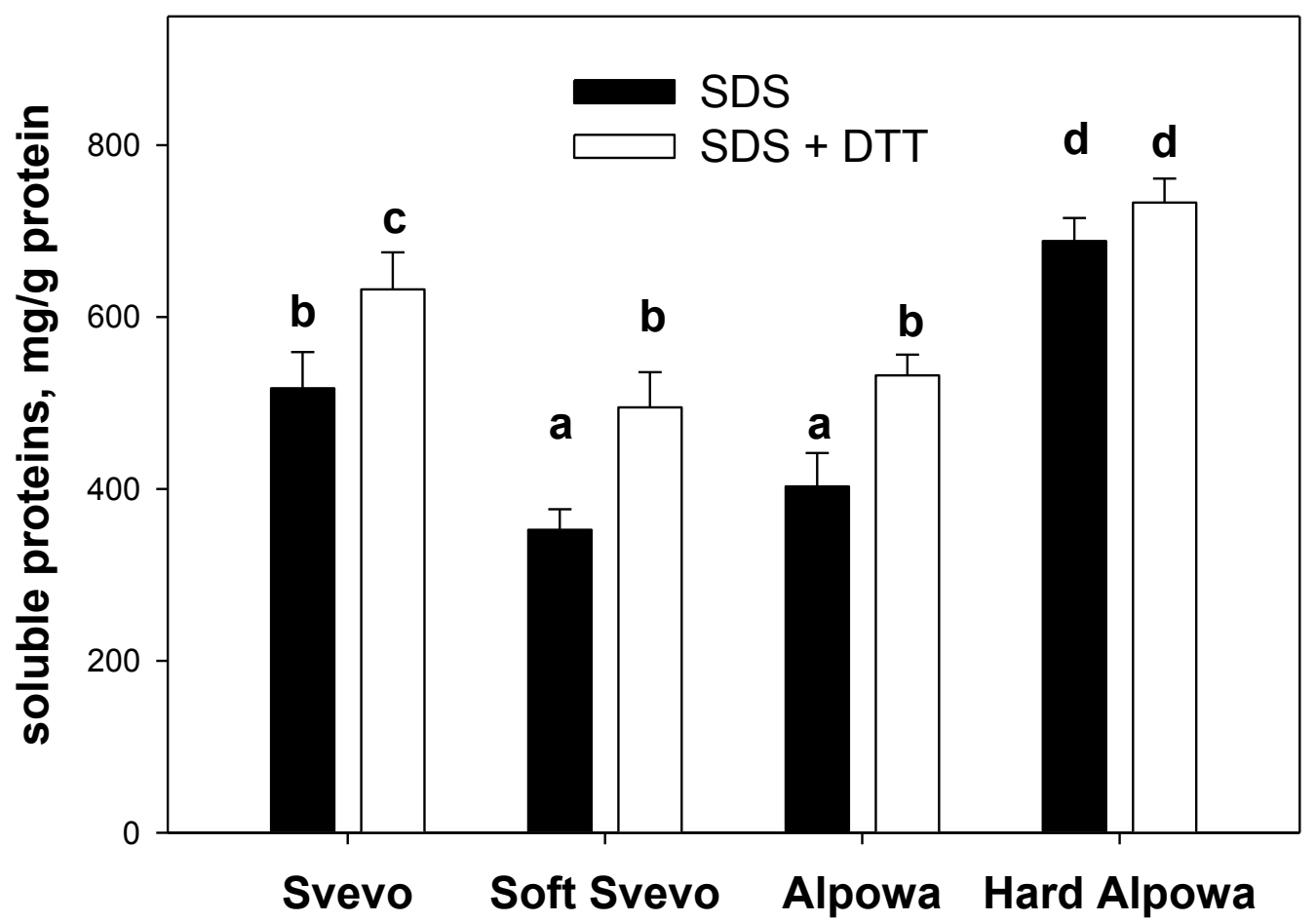

FIGURE 2 


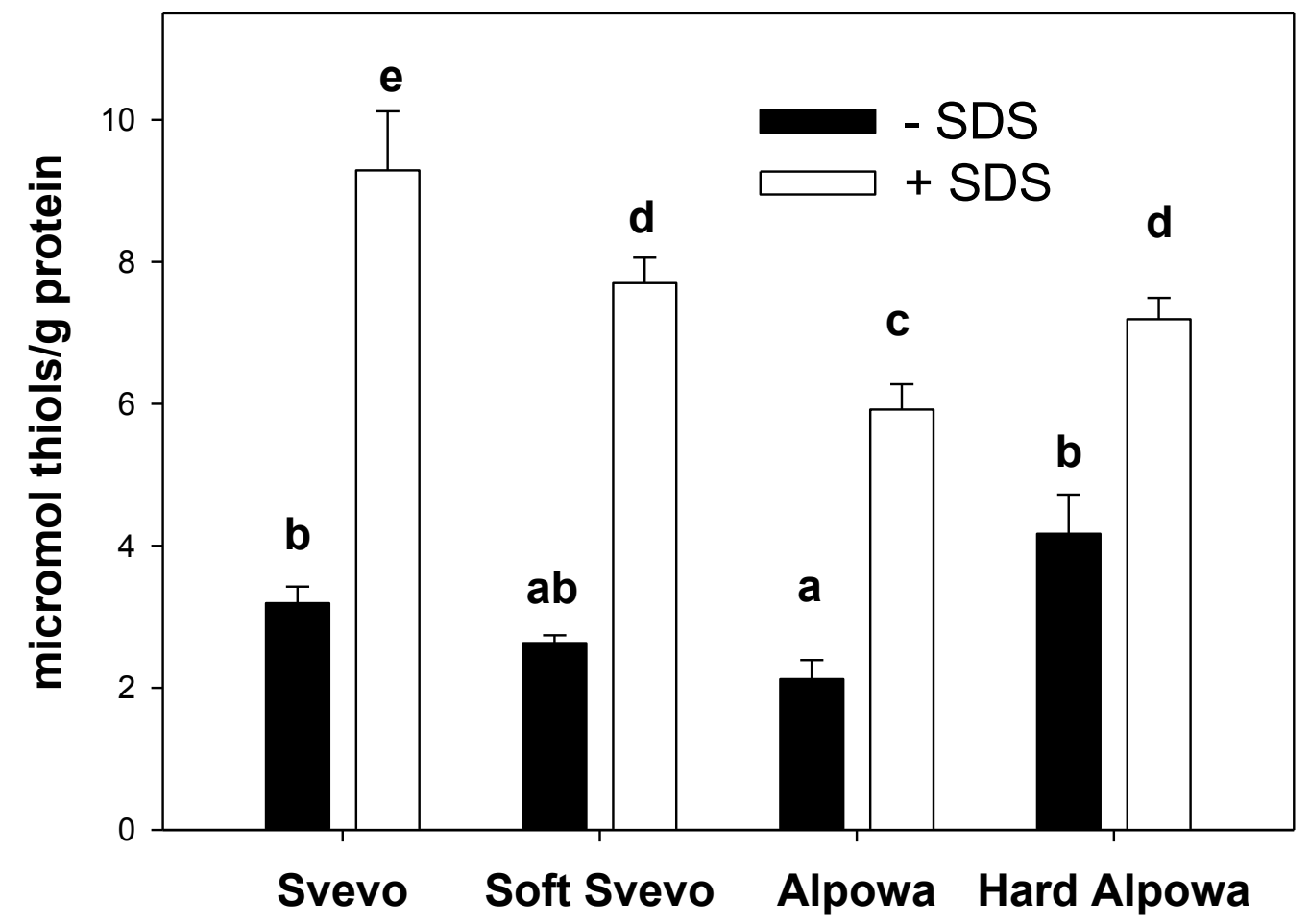

Figure 3. 


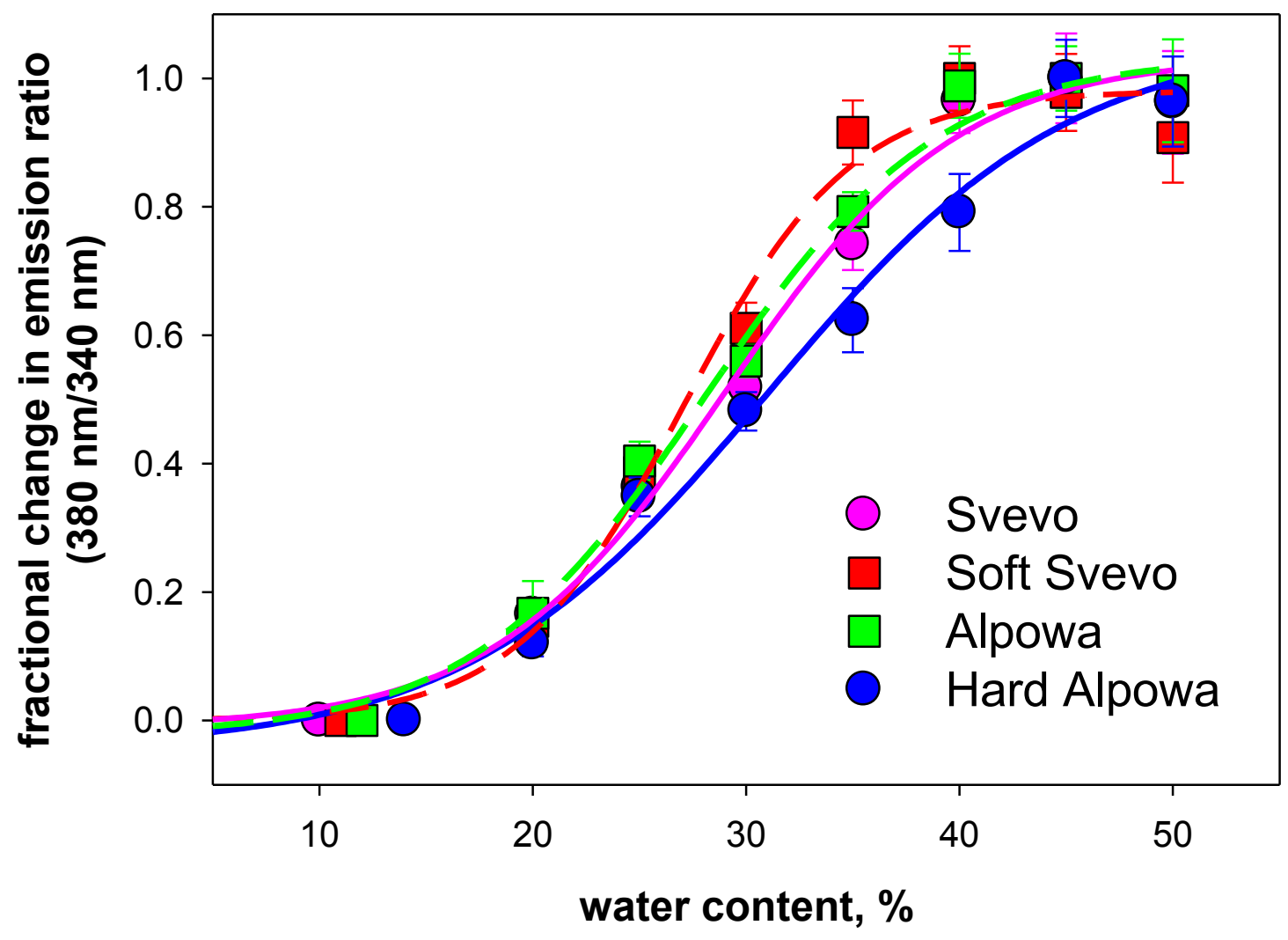

Figure 4. 


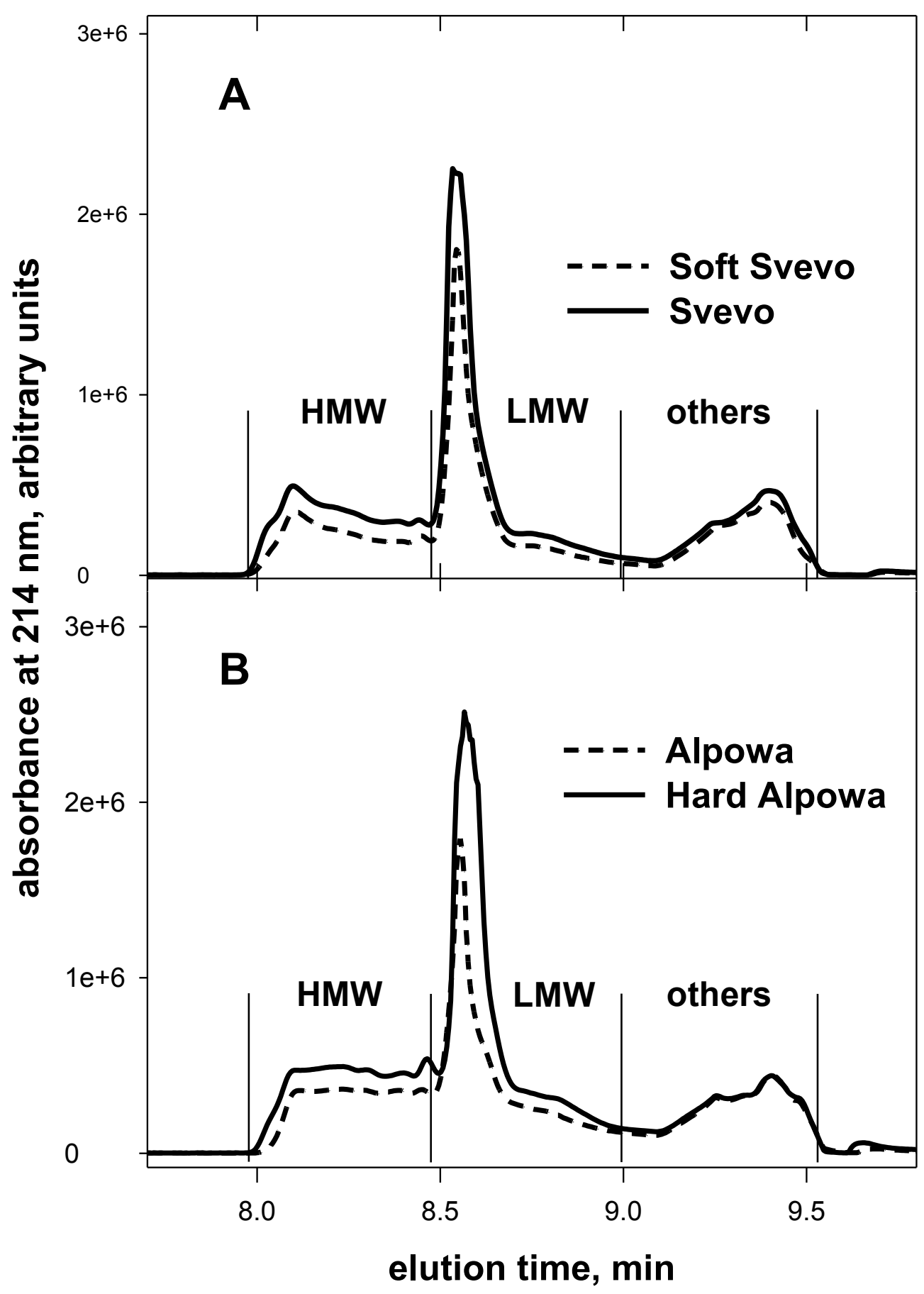

Figure 5. 

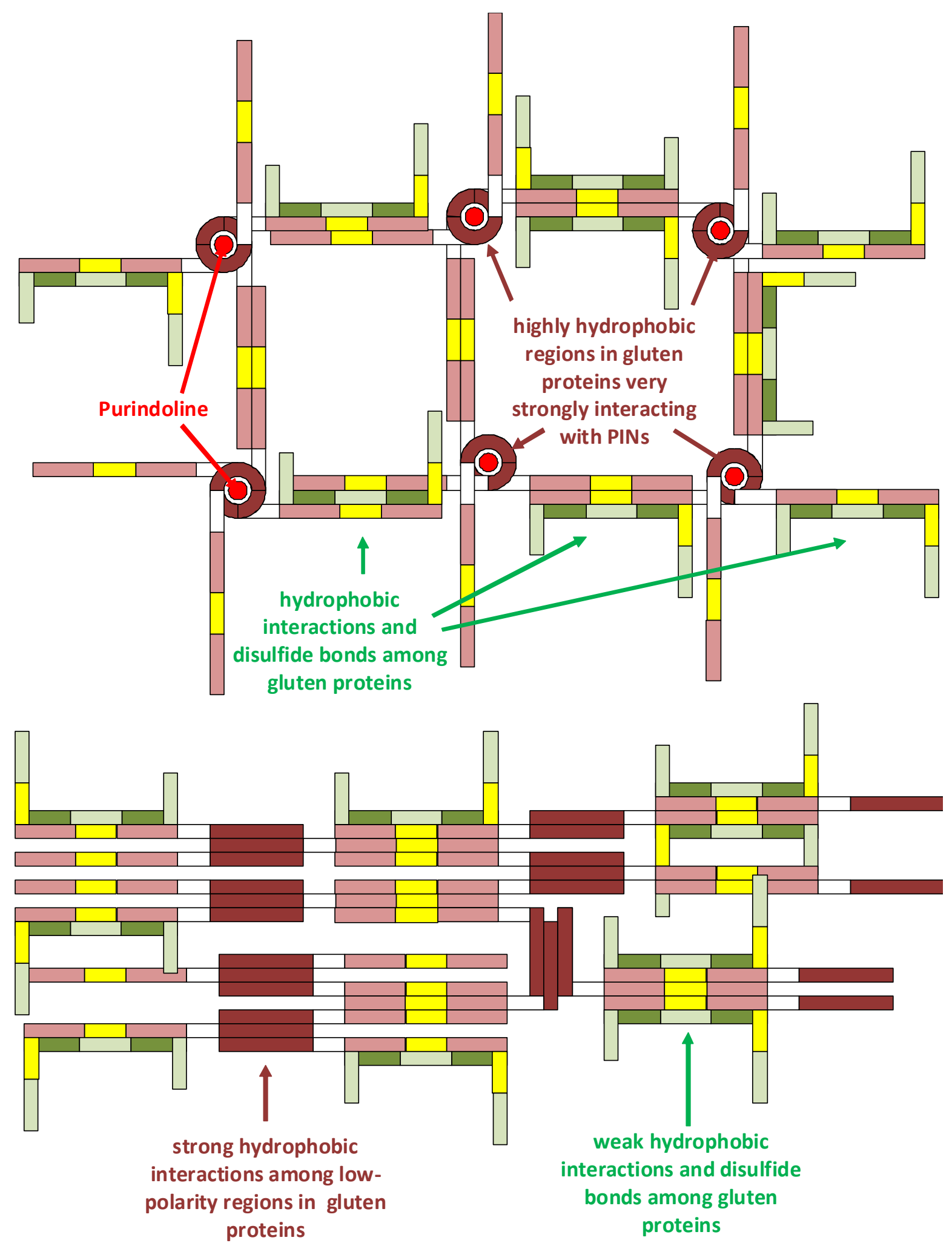

Figure 6 